\title{
Synthesis, characterization, optical and electrochemical band gaps of green poly(azomethine-ester)s containing oxalyl and succinyl units
}

\author{
KEVSER TEMIZKAN and İSMET KAYA* \\ Polymer Synthesis and Analysis Laboratory, Department of Chemistry, Çanakkale Onsekiz Mart University, \\ 17020 Çanakkale, Turkey \\ *Author for correspondence (kayaismet@ hotmail.com)
}

MS received 10 August 2017; accepted 12 July 2018; published online 4 April 2019

\begin{abstract}
A new series of poly(azomethine-ester)s (PAZ-E)s with different (turning ortho, meta and para) positions were synthesized by condensation polymerization. The chemical structure of polymers was verified by ${ }^{1} \mathrm{H}-\mathrm{NMR},{ }^{13} \mathrm{C}-\mathrm{NMR}$, FTIR and UV-Vis measurements. Electrochemical characteristics of the corresponding polymers were obtained with cyclic voltammetric $(\mathrm{CV})$ analysis. Thermal characteristics of the obtained polymers were analysed by TG-DTA, DMA and DSC measurements. The first degradation temperature values of PAZ-E compounds were found between 198 and $250^{\circ} \mathrm{C}$ from TGA measurements. Photophysical characteristics of the obtained polymers were explained with photoluminescence (PL) spectroscopy. Molecular weight distributions of (PAZ-E)s were obtained by gel permeation chromatographic (GPC) analysis. Two- and three-dimensional (2D and 3D) properties and images of the synthesized (PAZ-E)s were analysed by SEM and AFM surface analysis techniques, respectively. Electrochemical band gap $\left(E_{\mathrm{g}}^{\prime}\right)$ values of (PAZ-E)s P-9, P-10, P-11, P-12, $\mathrm{P}-13$ and $\mathrm{P}-14$ were calculated as $2.58,2.14,1.90,2.06,1.89$ and $1.69 \mathrm{eV}$, respectively. The $E_{\mathrm{g}}^{\prime}$ values of the (PAZ-E)s were found to be quite low.
\end{abstract}

Keywords. Poly(azomethine-ester); schiff base; photophysical behaviour; electrochemical properties; thermal degradation; surface morphologies.

\section{Introduction}

Polyesters with polymeric materials are studied widely from their advantageous structures in making textile-fibres, films, surface technologies and plastic supplies, resulting from the interest to find out their properties. Additionally, broad chemical and mechanical properties can exist in long chains by variation of hard or soft terminations, concentration or by using thermal and mechanical procedures [1-4]. Aromatic imine polymers are known as strong capacity polymers with conductive properties, high thermal stability, high mechanical durability and good optoelectronic properties. It is difficult to obtain long molecular chains and consistent constructional and high molecular properties in polymers because they have low solubility in some solvents and more particularly as hope-inspiring materials with optoand photo-electronic applications [5-14]. Polyesters with aliphatic and ether groups as a part of the chain are more useful because of their high mechanical, electrical and thermal properties [15-21]. Poly(azomethine-ester)s (PAZ-E)s containing imine and ester groups in the main chain have demonstrated double degradation properties. The degradation degree of the polymer increases with the number of imine bonds in the polymer chain. They are thermodynamically stable and preserve their molecular weight and their mechanical strength in air [22]. Aromatic (PAZ-E)s are interesting sort of conjugated polymers due to many remarkable properties, such as thermal resistance, nonlinear optical behaviour, semi-conductivity, electroluminescence, liquid crystallinity and fibre-forming ability [22,23]. Depending on these properties, polymers have technical applications, for instance, in anode and cathode batteries, semi-conductors, energy storage devices, conversion equipment, etc. Some of them have spatially expanded $\pi$-bonding conjugations and find use in aerospace mechanics, opto-electronics, laser and photovoltaic devices, as well as have sophisticated formation ability and forceful corrosion barriers [24-29].

The aim of this research was to synthesize different (PAZE)s having a variety of aliphatic and ether spacers in polymer chains at ortho, meta and para positions to discuss the influence of positions and types of functional groups on the photophysical, thermal, mechanical, electrochemical and surface properties.

\section{Experimental}

\subsection{Chemicals}

4-Hydroxybenzaldehyde, $o$-, $m$ - and $p$-xylenedibromide, 4-aminophenol, oxalylchloride and succinylchloride were 


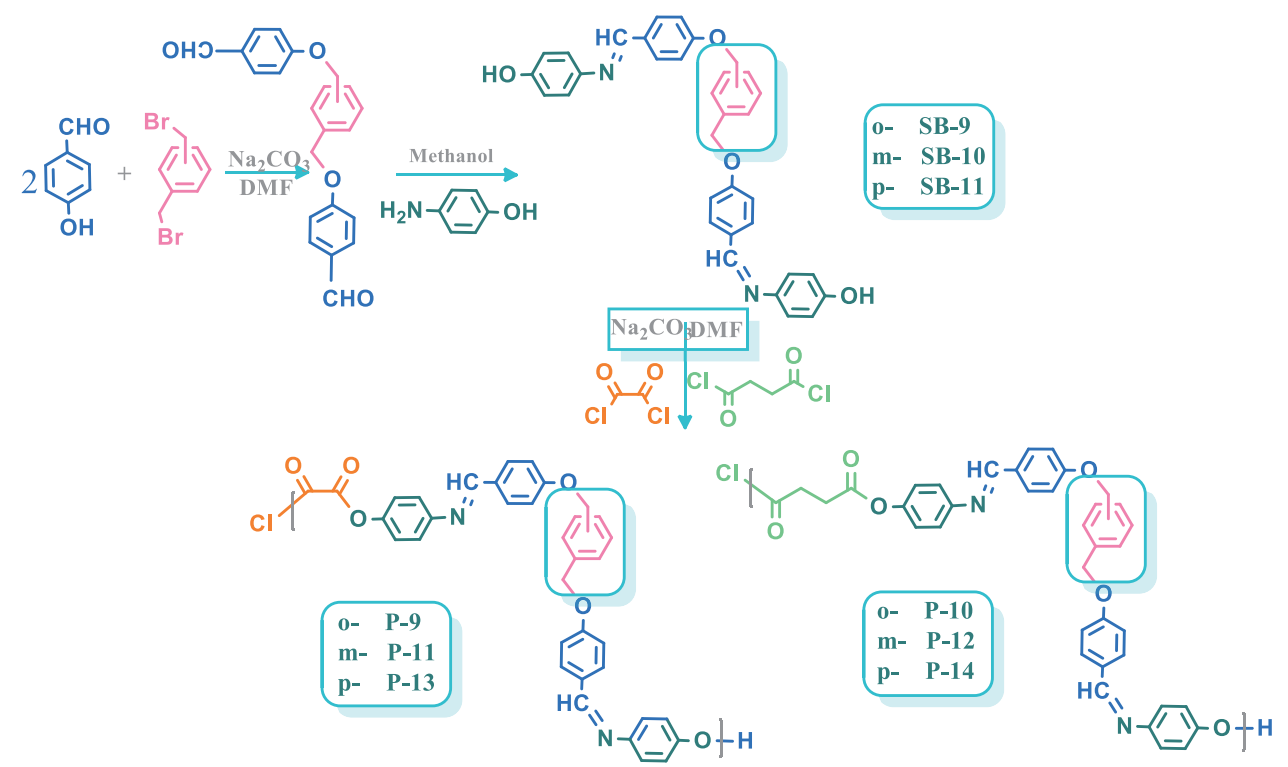

Scheme 1. Synthesis trends of the obtained SBs and (PAZ-E)s.

supplied by Fluka. Sodium carbonate $\left(\mathrm{Na}_{2} \mathrm{CO}_{3}\right)$, dimethylformamide (DMF), methanol $(\mathrm{MeOH})$, acetonitrile, ethyl acetate, hexane, tetrahydrofuran (THF) and dimethyl sulfoxide (DMSO) were bought from Merck Chem. Co. (Germany).

\subsection{Synthesis procedure of Schiff bases and (PAZ-E)s}

The preparation of the Schiff base (SB) monomers (SB-9, SB10 and SB-11) was performed by condensation reactions. The structures of these products and their many characteristics are shown in scheme 1.

SB was prepared by a two-step condensation reaction. In the first step, 4-hydroxybenzaldehyde $(0.04 \mathrm{~mol})$ and dry DMF $(25 \mathrm{ml})$ were put into a $250 \mathrm{ml}$ three different roundbottomed flasks, respectively. An amount of $0.02 \mathrm{~mol}$ of $\mathrm{Na}_{2} \mathrm{CO}_{3}$ was dissolved in DMF $(5 \mathrm{ml})$ and it was poured into this mixture and then, it was heated $\left(60^{\circ} \mathrm{C}, 1 \mathrm{~h}\right)$ with stirring under an argon atmosphere. An amount of $0.02 \mathrm{~mol}$ of $o-, m$ - and $p$-xylene dibromides, dissolved in DMF $(30 \mathrm{ml})$, was incorporated into these mixtures. These reaction solutions were slowly poured into $150 \mathrm{ml}$ of chloroform and the settled pure products were collected. In the second step, the obtained three different dialdehydes were dissolved in methanol $(25 \mathrm{ml})$ in three different flasks. An amount of $0.02 \mathrm{~mol}$ of 4-aminophenol, dissolved in methanol $(5 \mathrm{ml})$, was poured into these mixtures and heated $\left(60^{\circ} \mathrm{C}, 6 \mathrm{~h}\right)$, slowly. These mixtures were filtered, distilled from acetonitrile and they were dried in a vacuum oven [30]. The yields of purely synthesized SB-9, SB-10 and SB-11 were found to be 73, 74 and 74\%, respectively.

Synthesized (PAZ-E)s were obtained by the condensation reactions of the formed SBs with oxalyl chloride and succinyl chloride in six different flasks. (PAZ-E)s were also abbreviated as P-9, P-10, P-11, P-12, P-13 and P-14. Synthesis stages of (PAZ-E)s are as follows: SBs $(0.04 \mathrm{~mol})$ and dry DMF $(25 \mathrm{ml})$ were placed into $250-\mathrm{ml}$ round-bottom flasks. An amount of 0.02 mol of $\mathrm{Na}_{2} \mathrm{CO}_{3}$, dissolved in DMF (5 $\mathrm{ml})$, was poured into this mixture and heated $\left(60^{\circ} \mathrm{C}, 1 \mathrm{~h}\right)$ with stirring under an argon atmosphere. $0.02 \mathrm{~mol}$ of oxalylchloride and succinylchloride dissolved in DMF (30 ml) and then these solutions were added separately into reaction mixtures in round-bottom flasks. The temperature was increased to $150^{\circ} \mathrm{C}$ and the reaction mixtures were placed under an argon atmosphere for $5 \mathrm{~h}$ to complete the reaction. These reaction solutions were decanted into $200 \mathrm{ml}$ of chloroform and the settled pure products were collected [31]. The obtained (PAZE)s were washed in methanol $(25 \mathrm{ml})$. These products were dried in a vacuum oven at $70^{\circ} \mathrm{C}$ for $36 \mathrm{~h}$. The pure yields of P-9, P-10, P-11, P-12, P-13 and P-14 were found to be 70, 71, $70,70,72$ and $71 \%$, respectively.

\subsection{Characterization techniques}

Infrared spectral measurements were executed using a PerkinElmer Spectrum One FTIR system and obtained in a granulated form under room conditions with universal ATR sampling peripherals between wavelengths 4000 and $650 \mathrm{~cm}^{-1}$. UV-Vis analysis of pure products was realized by using an AnalytikJena Specord 210 Plus at room temperature in DMF solvent. Photoluminescence (PL) properties of the synthesized chemicals were analysed in DMF solution using a Shimadzu RF-5301PC spectrofluorometer device. A slit width was selected as $5 \mathrm{~nm}$ for all the sample solutions. ${ }^{1} \mathrm{H}$ - and ${ }^{13} \mathrm{C}$-NMR spectra were recorded using a Bruker Avance DPX-400 and 100.6 MHz by using $\mathrm{DMSO}_{\mathrm{d} 6}$ as a solvent under room conditions. The analysis 

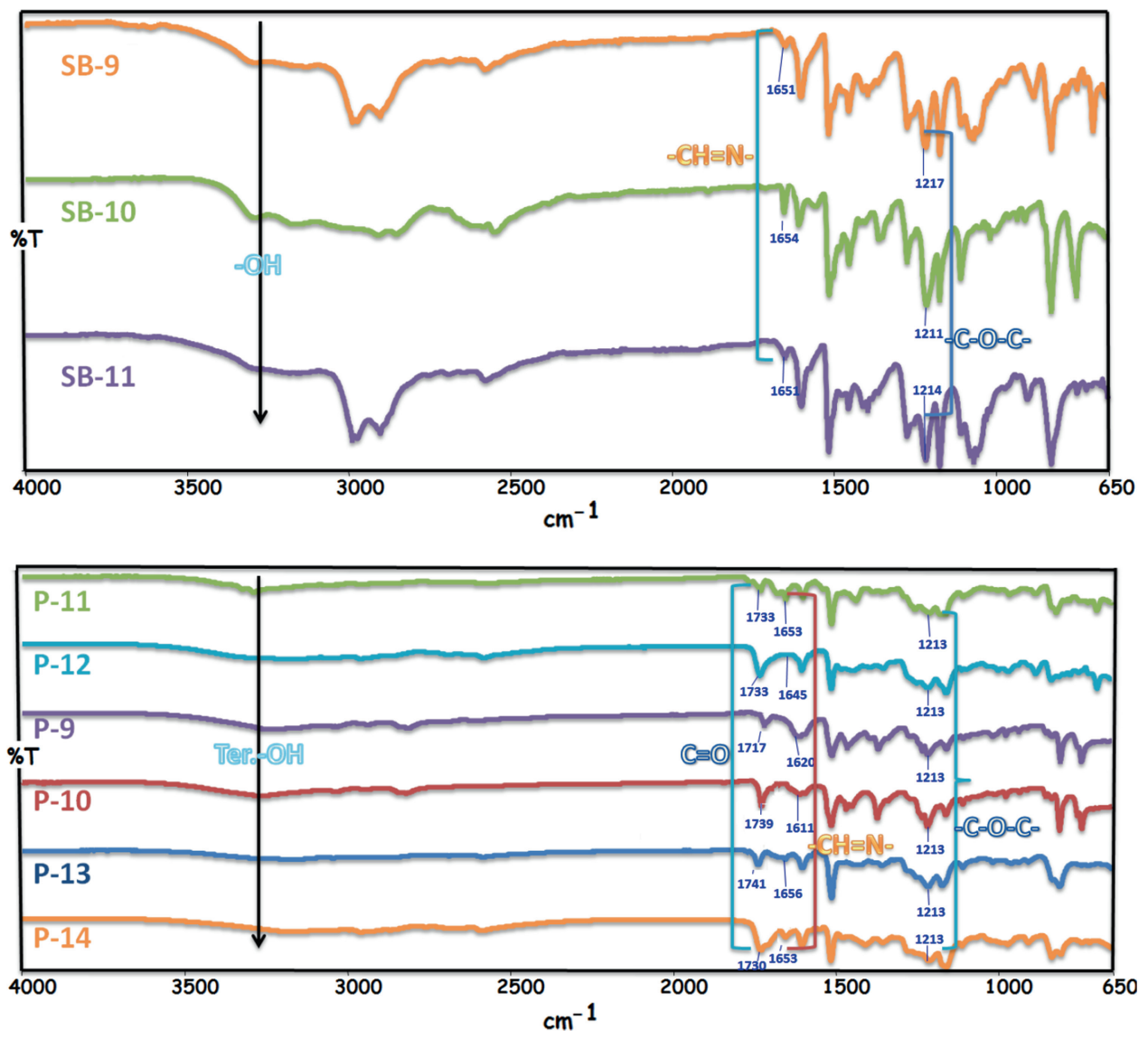

Figure 1. FTIR spectra of the synthesized SBs and (PAZ-E)s.

of GPC was executed using a Shimadzu 10AVp series HPLC-GPC system with polystyrene standard. All GPC analyses were performed by $\mathrm{DMF} / \mathrm{MeOH}(\mathrm{v} / \mathrm{v}, 4 / 1)$ at $55^{\circ} \mathrm{C}$. Electrochemical analysis of pure products was performed by using a CHI 660C Electrochemical Analyzer (CH Instruments, Texas, USA) in $0.1 \mathrm{~mol}^{-1}$ tetrabutylammonium hexafluorophosphate/supporting electrolyte solution, under an argon atmosphere under room conditions. A glassy carbon electrode was used as a working electrode and at the same time Ag wire was used as a reference electrode and Pt wire was used as a counter electrode for all cyclic voltammogram (CV) analysis. The highest and lowest occupied molecular orbital (HOMO-LUMO) energy levels and the calculated oxidation and reduction onset peak values were measured [32]. The surface morphology of (PAZ-E)s was recorded by using a Jeol JSM-7100F Schottky field emission scanning electron microscope. A sputter coating process was used to create a thin gold/palladium film onto the polymer particles. Topography and $3 \mathrm{D}$ images of the polymeric films were recorded using an atomic force microscope (AFM) Alpha 300 A (WITec, Ulm, Germany). Issued surface areas of (PAZ-E)s were scanned angularly by using a non-contact mode cantilever (AC, $42 \mathrm{~N} / \mathrm{m}, 285 \mathrm{kHz}$ ). Thermal characterization was performed by a Perkin Elmer diamond thermal analysis system. Thermogravimetric analysis (TGA) was carried out between
10 and $1000^{\circ} \mathrm{C}$ (in $\mathrm{N}_{2}\left(200 \mathrm{ml} \mathrm{min}^{-1}\right)$, rate $\left.10^{\circ} \mathrm{C} \mathrm{min}^{-1}\right)$. DSC measurements were performed by using Perkin Elmer Pyris Sapphire within the temperatures of $20-450^{\circ} \mathrm{C}$ (in $\mathrm{N}_{2}(200$ $\mathrm{ml} \mathrm{min}-1$ ), rate $10^{\circ} \mathrm{C} \mathrm{min}^{-1}$ ). DMA tests were carried out by a Perkin Elmer Pyris Diamond DMA 115 V using a single cantilever bending mode at a frequency of $1 \mathrm{~Hz}$, at a heating rate of $3^{\circ} \mathrm{C} \min ^{-1}$ and in the range of $20-350{ }^{\circ} \mathrm{C}$ under a

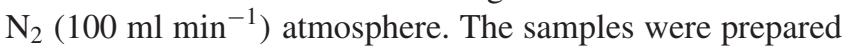
as follows: $0.2 \mathrm{~g}$ of (PAZ-E)s was placed into the titanium clamp (supplied from Triton Technology Ltd., United Kingdom) and extended, followed by closing of the clamps at both sides [30].

\section{Results and discussion}

\subsection{The structure analyses of compounds}

FTIR spectra of SBs are nearly similar to each other in view of functional group similarities. FTIR spectra of SB-9, SB10 and SB-11 have a peak at 1217, 1211 and $1214 \mathrm{~cm}^{-1}$ related to ether group ( $-\mathrm{C}-\mathrm{O}-\mathrm{C}-)$, respectively. Last four spectra of (PAZ-E)s presented strong bands at around 1733 and $1717 \mathrm{~cm}^{-1}$ after the polymerization with the functional group of $\mathrm{C}=\mathrm{O}$ ester, which confirmed the achievement of 
A
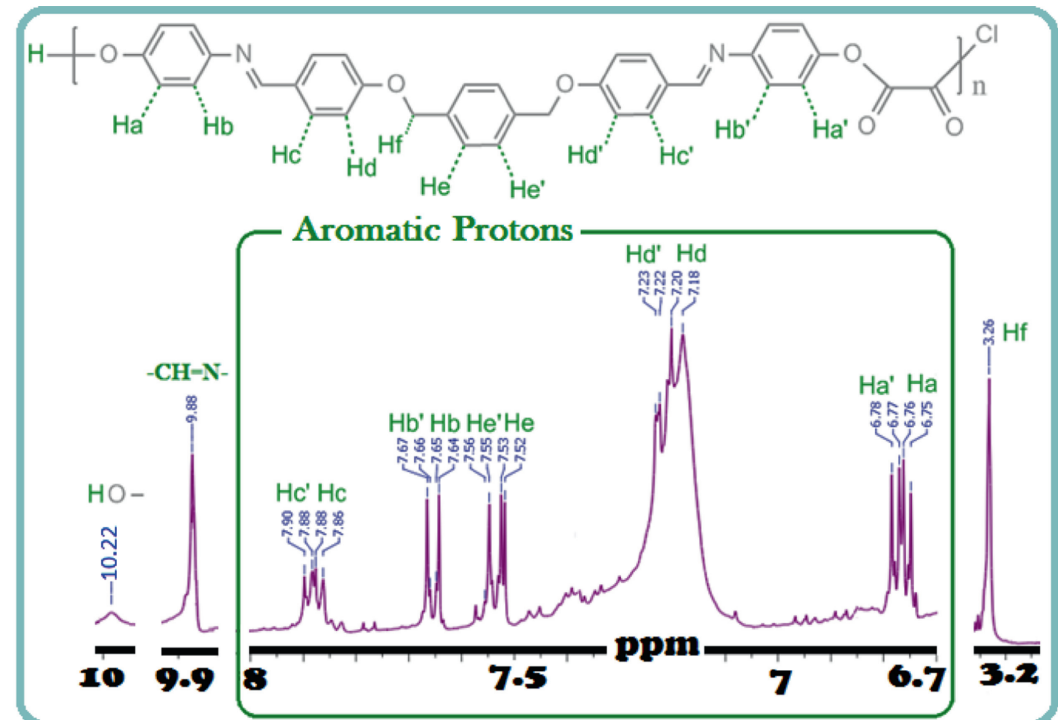

B

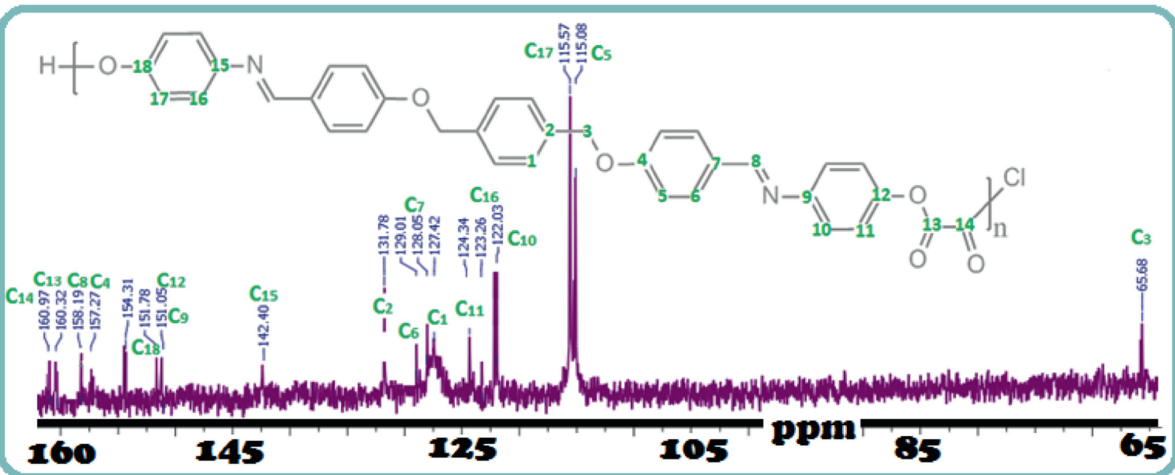

Figure 2. (A) ${ }^{1} \mathrm{H}-\mathrm{NMR}$ and (B) ${ }^{13} \mathrm{C}-\mathrm{NMR}$ spectra of P-13.

polymerization $[28,32]$ to form $\mathrm{P}-9, \mathrm{P}-10, \mathrm{P}-11, \mathrm{P}-12, \mathrm{P}-13$ and $\mathrm{P}-14$, respectively, as illustrated in figure 1 . The bending vibration bands of ether $(-\mathrm{C}-\mathrm{O}-\mathrm{C}-$ ) groups were observed at $1213 \mathrm{~cm}^{-1}$ in the structures of (PAZ-E)s. All spectra of (PAZE)s have similar stretching and bending vibration peaks.

The aromatic and aliphatic proton signals in the ${ }^{1} \mathrm{H}-\mathrm{NMR}$ spectra of P-13 were observed at about 7.90-6.75 and 3.26 ppm. An imine peak was observed at $9.88 \mathrm{ppm}$, while a small peak of terminal -OH was observed at $10.22 \mathrm{ppm}$ (figure 2). According to the ${ }^{13} \mathrm{C}-\mathrm{NMR}$ spectrum of $\mathrm{P}-13$, PAZ-E carbonyl and imine carbon atoms were observed at 160.97, 160.32, 157.27 and $158.19 \mathrm{ppm}$, respectively. An aliphatic $-\mathrm{CH}_{2}$ signal of P-13 was seen at $65.68 \mathrm{ppm}$. Aromatic carbon atoms were also observed between 157.27 and $115.08 \mathrm{ppm}$ (figure 2). NMR analysis results confirmed the occurrence of all (PAZ-E)s, similarly.

The number average molecular weight $\left(M_{\mathrm{n}}\right)$, weight average molecular weight $\left(M_{\mathrm{w}}\right)$ and the polydispersity index (PDI $=M_{\mathrm{w}} / M_{\mathrm{n}}$ ) values of (PAZ-E)s were calculated via gel permeation chromatography (GPC). The calibration of the instrument was completed by a mixture of polystyrene
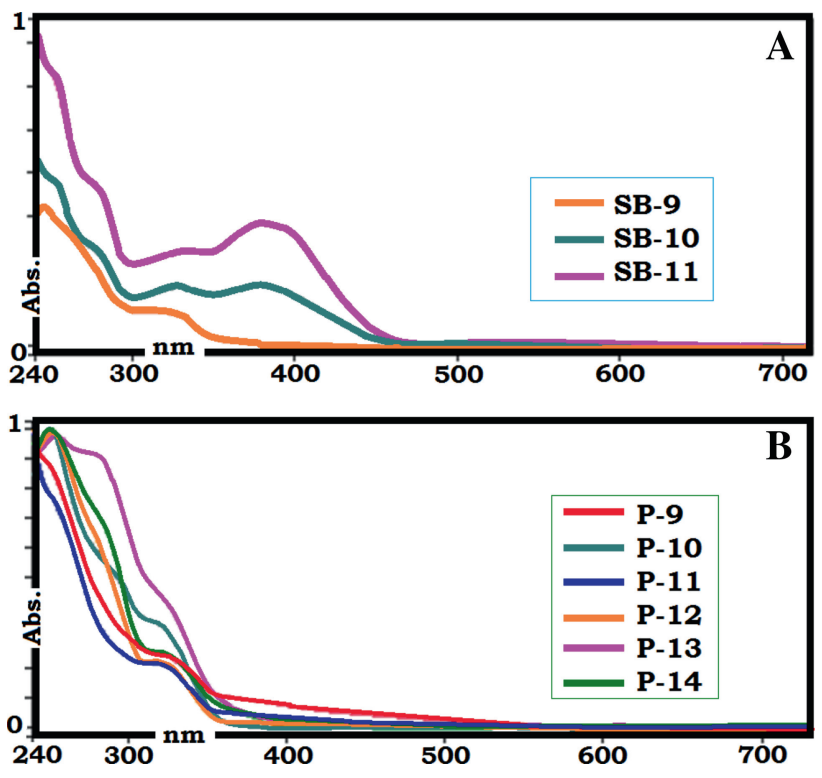

Figure 3. UV-Vis spectra of (A) (SB)s and (B) (PAZ-E)s. 
standards (Polymer Laboratories; the peak molecular weights, $M_{\mathrm{p}}$, between 162 and 60.000). The $M_{\mathrm{n}}, M_{\mathrm{w}}$ and PDI values of P-9, P-10, P-11, P-12, P-13 and P-14 (PAZ-E)s were calculated as 18200, 30300, 13800, 16400, 18900 and 14200 Dalton; 24800, 36600, 18100, 23500, 27200 and 18500 Dalton; and 1.36, 1.21, 1.31, 1.43, 1.44 and 1.30 , respectively.

To investigate the electronic transition of the (PAZ-E)s, UV-Vis absorption and PL measurements were carried out. Figure 3 demonstrates UV-Vis spectra of (PAZ-E)s and SBs, and their findings are also tabulated in table 1. UV-Vis spectra of SBs show three absorption bands. The first absorption band is observed between 250 and $290 \mathrm{~nm}$ due to the $\pi \rightarrow \pi^{*}$ transition of benzene linkages. The second absorption band is observed between 290 and $355 \mathrm{~nm}$ due to $n \rightarrow \pi^{*}$ transition of ether linkages. The third absorption band is observed in the range of 355-465 nm due to the $\pi \rightarrow \pi^{*}$ transitions of azomethine linkages. As for those UV-Vis spectra of (PAZ-E)s, three absorption bands were observed. The first absorption band is observed between 240 and $270 \mathrm{~nm}$ due to the $\pi \rightarrow \pi *$ transition of benzene linkages. The second absorption band is observed between 275 and $340 \mathrm{~nm}$ due to the $\pi \rightarrow \pi^{*}$ transition of ester linkages. The third absorption band is observed in the range of 340-580 nm due to the $\pi \rightarrow \pi^{*}$ and $n \rightarrow \pi^{*}$ transitions

Table 1. Optical band gaps, $\lambda_{\max }$ and $\lambda_{\text {onset }}$, values of the obtained SBs and their (PAZ-E)s.

\begin{tabular}{lccc}
\hline Compounds & $\lambda_{\max .}(\mathrm{nm})$ & $\lambda_{\text {onset }}(\mathrm{nm})$ & $E_{\mathrm{g}}^{\mathrm{a}}(\mathrm{eV})$ \\
\hline SB-9 & $265,320,399$ & 462 & 2.68 \\
SB-10 & $279,330,381$ & 558 & 2.22 \\
SB-11 & $277,331,382$ & 465 & 2.67 \\
P-9 & $245,281,324$ & 570 & 2.17 \\
P-10 & $243,282,325$ & 483 & 2.57 \\
P-11 & $251,284,322$ & 522 & 2.38 \\
P-12 & $254,284,326$ & 532 & 2.33 \\
P-13 & $253,283,327$ & 494 & 2.51 \\
P-14 & $251,284,332$ & 480 & 2.59 \\
\hline
\end{tabular}

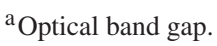

related to azomethine linkages [33]. The appearance of changes of ortho, meta and para positions in (PAZ-E)s having different colours in DMF solutions under sunlight is shown in figure 4 . The colours of solutions of (PAZ-E)s were observed as green, blue and pink under sunlight and at room temperature.

\subsection{Fluorescence properties}

Fluorescence analysis was performed by a Shimadzu RF5301PC spectrofluorophotometer system. PL spectral analyses were achieved in DMF. The prepared solution concentrations of the (PAZ-E)s were between 0.2 and $0.025 \mathrm{mg}$ $1^{-1}$ and slit widths were between 3 and $5 \mathrm{~nm}$ (for P-9, P-10, P-13 and P-14) and (for P-11 and P-12) for all measurements, respectively.

PL spectroscopic analyses were used to estimate the fluorescence properties of the (PAZ-E)s (figure 5). It is seen that PL spectra of the P-9, P-10, P-13 and P-14 (PAZ-E)s showed an emission maximum. Emission maxima of the (PAZ-E)s series (table 2) were found to be P-9 (397 nm), P-10 (377 nm), P-13 (418 nm) and P-14 (438 nm) at maximum concentrations, respectively, as stated in the literature [34]. Conjugation on the ester-phenyl-imine section could be due to the chlorophore that was responsible for the fluorescence properties. Whereas, P-11 and P-12 (PAZE)s did not have fluorescence properties, these spectra are shown in figure 5. The order of fluorescence properties is meta $>$ para $>$ ortho for (PAZ-E)s, respectively.

The PL intensity value of (PAZ-E)s containing aromatic units was found to be higher than those (PAZ-E)s containing aliphatic units [35].

\subsection{Electrochemical properties}

Electrochemical characteristics of SBs and (PAZ-E)s are determined from cyclic voltammetry (CV) measurements with a three electrode electrochemical cell. The HOMOLUMO values and electrochemical band gap $\left(E_{\mathrm{g}}^{\prime}\right)$ values of (PAZ-E)s were identified by solving electronic structures of the obtained compounds. Figure 6 shows the cyclic curves

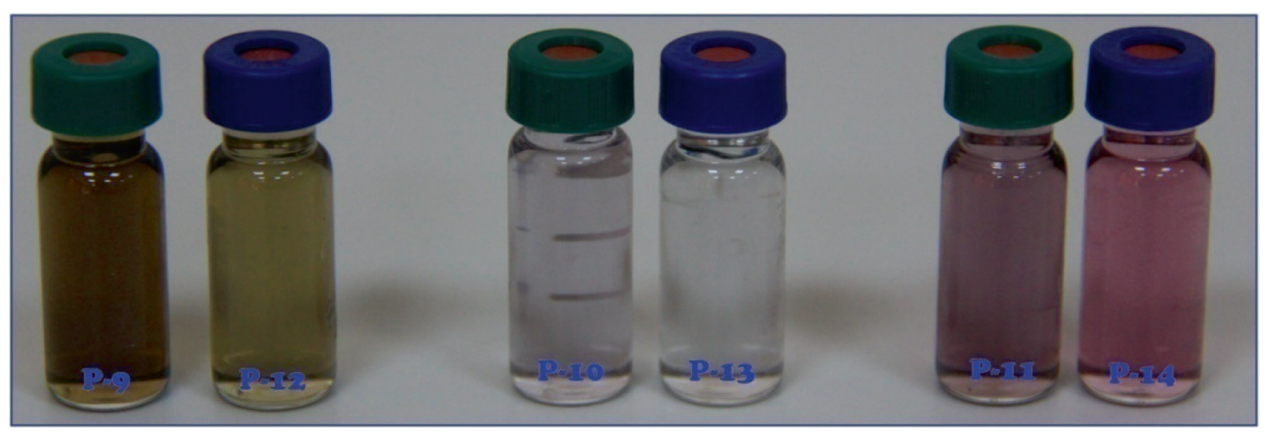

Figure 4. Appearance of turning ortho-, meta- and para-positioned (PAZ-E)s having different colours in DMF solution under sunlight. 

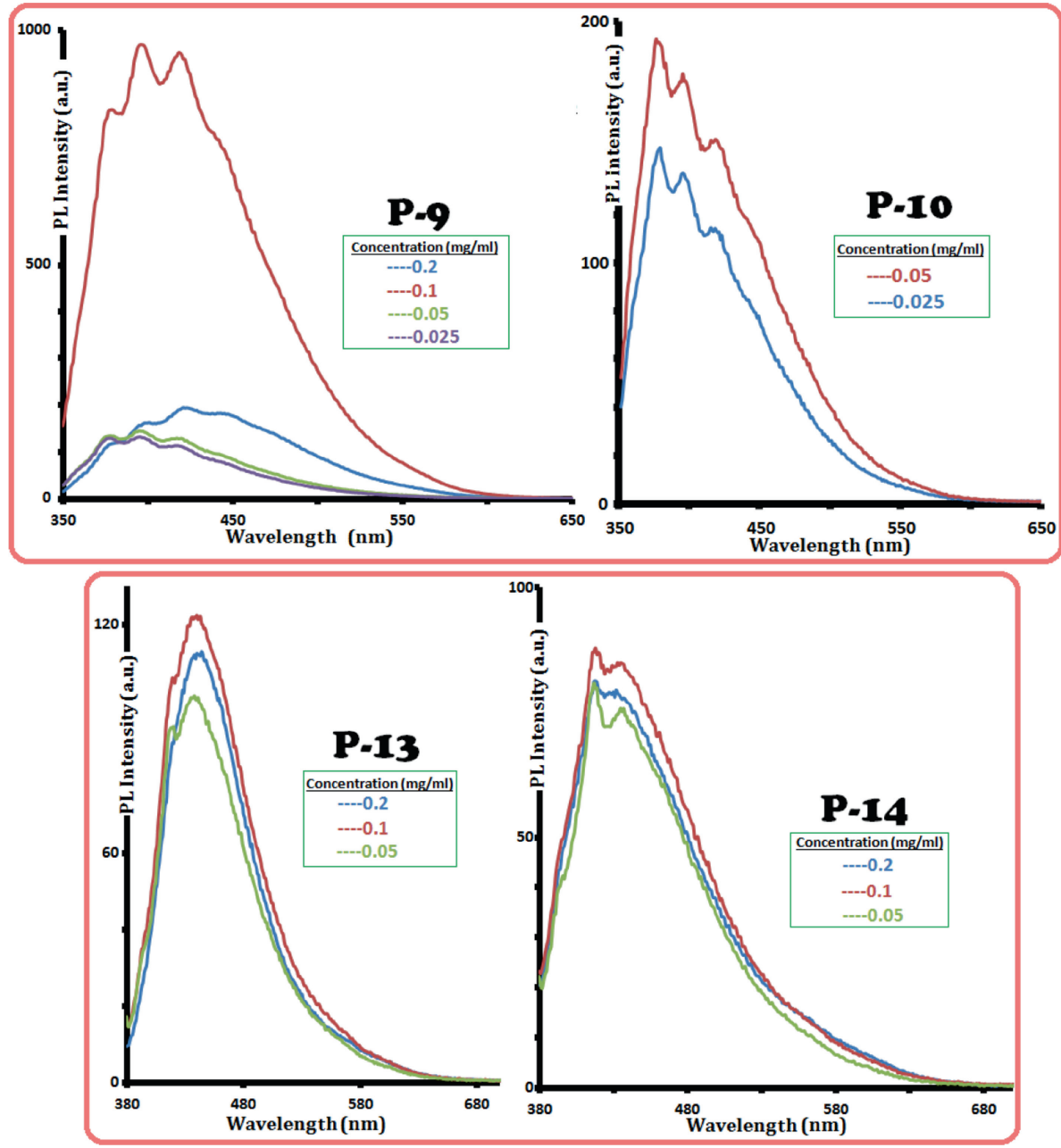

Figure 5. PL spectra of (PAZ-E)s.

Table 2. Photoluminescence properties of (PAZ-E)s.

\begin{tabular}{llccl} 
(PAZ-E)s & Concentration $\left(\mathrm{mg} \mathrm{ml}^{-1}\right)$ & $\lambda_{\mathrm{Ex}}^{\mathrm{a}}$ & $\lambda_{\max (\mathrm{Em})}^{\mathrm{b}}$ & $I_{\mathrm{Em}}^{\mathrm{c}}$ \\
\hline P-9 & 0.1 & 347 & 397 & 975 \\
P-10 & 0.05 & 341 & 377 & 193 \\
P-13 & 0.1 & 370 & 418 & 90 \\
P-14 & 0.1 & 370 & 438 & 124 \\
\hline
\end{tabular}

${ }^{\mathrm{a}}$ Excitation wavelength for emission.

${ }^{b}$ Maximum emission wavelength.

${ }^{\mathrm{c}}$ Maximum emission intensity.

of the polyesters and their SBs. The HOMO, LUMO and $E_{\mathrm{g}}^{\prime}$ values of the synthesized products were identified as in ref. [36], and the calculated results are summarized in table 3 . The lowest $E_{\mathrm{g}}^{\prime}$ values were observed in para substituted (PAZ-E)s (P-13 and $\mathrm{P}-14$ ).

The onset oxidation potential $\left(E_{\text {ox. }}\right)$ of the obtained SBs and (PAZ-E)s are in the range of 1.4699-1.4511 V and 1.4822$1.1699 \mathrm{~V}$, respectively. The HOMO level of the obtained (PAZ-E)s was specified between -5.8599-(-5.8411) and $-5.8722-(-5.5599) \mathrm{eV}$, respectively. Similarly, the onset reduction potentials $\left(E_{\text {red. }}\right)$ of the $(\mathrm{PAZ}-\mathrm{E}) \mathrm{s}$ and $\mathrm{SBs}$ were between $-1.3103-(-0.5918)$ and $-1.1549-(-0.5231) \mathrm{V}$ and the LUMO energy levels of these chemicals were identified in the range from -3.7982 to -3.0797 and from -3.8669 to $-3.2351 \mathrm{eV}$, respectively. The $E_{\mathrm{g}}^{\prime}$ of SB-9, SB-10 and SB-11 were also calculated as 2.76, 2.12 and $2.04 \mathrm{eV}$, respectively. However, the $E_{\mathrm{g}}^{\prime}$ values of P-9, P-10, $\mathrm{P}-11, \mathrm{P}-12, \mathrm{P}-13$ and P-14 were also calculated as 2.58, 2.14, 1.90, 2.06, 1.89 and $1.69 \mathrm{eV}$, respectively. As observed, the (PAZ-E)s have low $E_{\mathrm{g}}^{\prime} \mathrm{s}$. The $E_{\mathrm{g}}^{\prime}$ value of para positioned (PAZ-E)s was lower than those of ortho and meta positioned (PAZ-E)s. For this reason, P-13 and P-14 para (PAZ-E)s can be good candidates for electronic materials. These results have demonstrated the stability of (PAZ-E)s at the para position, because the second interactions are at the minimum levels between the units of (PAZ-E)s at the para position.

\subsection{Thermal properties}

Thermal characteristics of (PAZ-E)s were obtained using TGDTA and DSC analysis to clarify the thermal degeneration 

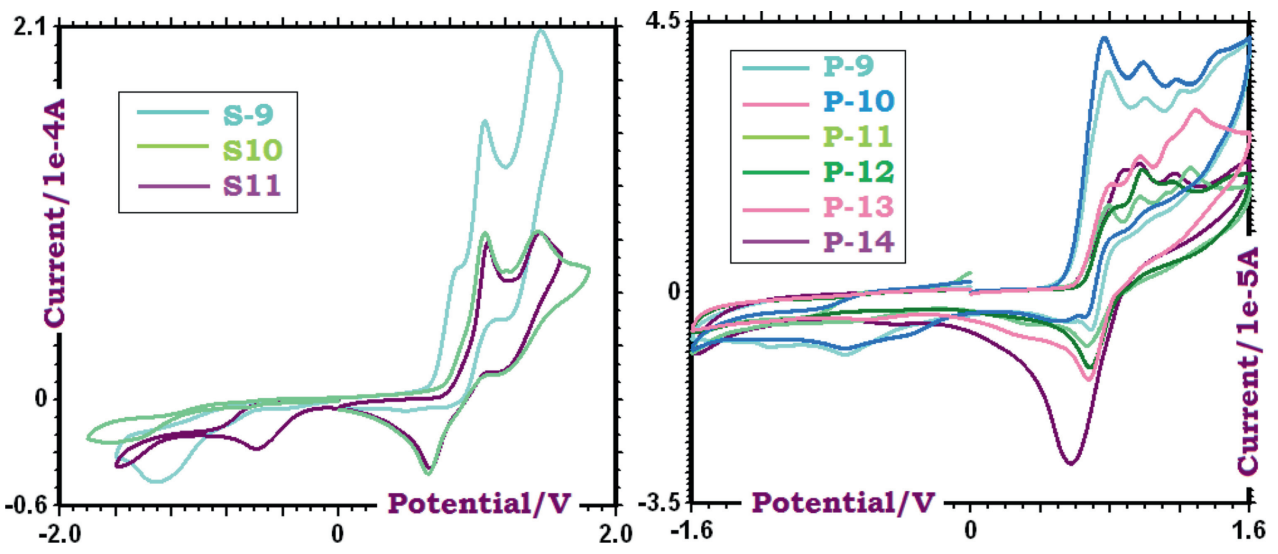

Figure 6. Cyclic voltammograms of SBs (scan rate: $100 \mathrm{mV} \mathrm{s}^{-1}$ ) and (PAZ-E)s (scan rate: $100 \mathrm{mV} \mathrm{s}^{-1}$ ).

Table 3. Electrochemical data of the obtained SBs and their (PAZ-E)s.

\begin{tabular}{lccccc}
\hline Compounds & $E_{\text {ox. }}(\mathrm{V})$ & $\mathrm{HOMO}^{\mathrm{a}}(\mathrm{eV})$ & $E_{\text {red. }}(\mathrm{V})$ & $\mathrm{LUMO}^{\mathrm{b}}(\mathrm{eV})$ & $E_{\mathrm{g}}^{\prime \mathrm{c}}(\mathrm{eV})$ \\
\hline SB-9 & 1.4511 & -5.8411 & -1.3103 & -3.0797 & 2.76 \\
SB-10 & 1.4699 & -5.8599 & -0.6481 & -3.7419 & 2.12 \\
SB-11 & 1.4511 & -5.8411 & -0.5918 & -3.7982 & 2.04 \\
P-9 & 1.4259 & -5.8159 & -1.1549 & -3.2351 & 2.58 \\
P-10 & 1.4299 & -5.8199 & -0.7104 & -3.6796 & 2.14 \\
P-11 & 1.2510 & -5.6410 & -0.6588 & -3.7312 & 1.90 \\
P-12 & 1.4822 & -5.8722 & -0.5804 & -3.8096 & 2.06 \\
P-13 & 1.2885 & -5.6785 & -0.6042 & -3.7858 & 1.89 \\
P-14 & 1.1699 & -5.5599 & -0.5231 & -3.8669 & 1.69 \\
\hline
\end{tabular}

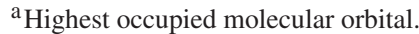

${ }^{\mathrm{b}}$ Lowest unoccupied molecular orbital.

${ }^{\mathrm{c}}$ Electrochemical band gap.

samples and glass transition temperature $\left(T_{\mathrm{g}}\right)$, respectively. TG-DTA data and curves of the (PAZ-E)s are shown in figure 7. The thermal analysis results of compounds are summarized in table 4. Figure 7 shows that P-9, P-10, P-11 and $\mathrm{P}-12$ degraded in three steps, while $\mathrm{P}-13$ and $\mathrm{P}-14$ degraded in two steps. With TGA curves of (PAZ-E)s, the onset temperatures of P-9, P-10, P-11, P-12, P-13 and P-14 were determined as $200,198,200,200,210$ and $250^{\circ} \mathrm{C}$, respectively. It is seen that the onset temperature $\left(T_{\mathrm{on}}\right)$ of the (PAZ-E)s reduced at high temperatures. These results have arised from molecular forms and molecule chain structures of obtained (PAZ-E)s. Char amounts of (PAZ-E)s were found to be 22, 22, 27, 25, 28 and $36 \%$ for P-9, P-10, P-11, P-12, P-13 and P-14, respectively, at $1000^{\circ} \mathrm{C}$. The thermal stabilities of para substituted (PAZ-E)s (P13 and P14) were found to be higher than those of ortho- and meta-substituted (PAZ-E)s. Both $T_{\text {on }}$ and char $\%$ of para-substituted (PAZ-E)s (P13 and P14) were higher than those of ortho- and meta-substituted (PAZ-E)s. The $T_{\text {on }}$ of PAZ-E [35] containing terephthaloyl units was found to be higher than those (PAZ-E)s containing aliphatic units. Thermal stabilities of (PAZ-E)s with the phenyl group were found to be better than those containing aliphatic units.

DSC curves of the (PAZ-E)s are shown in figure 8. As seen from DSC curves, the $T_{\mathrm{g}}$ of P-9, P-10, P-11 P-12, P13 and $\mathrm{P}-14$ were determined as $136,144,130,145,120$ and $125^{\circ} \mathrm{C}$, respectively. The highest $T_{\mathrm{g}}$ value is pertained to $\mathrm{P}-12$. The $\Delta C_{\mathrm{p}}$ values of $\mathrm{P}-9, \mathrm{P}-10, \mathrm{P}-11, \mathrm{P}-12, \mathrm{P}-13$ and $\mathrm{P}-14$ are determined as $0.143,0.118,0.022,0.023,0.020$ and $0.025 \mathrm{~J} \mathrm{~g} \mathrm{~g}^{-1} \mathrm{~K}^{-1}$, respectively. The $T_{\mathrm{g}}$ values of ortho- and meta-substituted (PAZ-E)s were nearly the same, but $T_{\mathrm{g}}$ values of para-substituted (PAZ-E)s (P13 and P14) were lower than the others.

\subsection{Dynamic mechanical properties}

DMA measurements of (PAZ-E)s containing azomethine bonds were used to investigate the mechanical properties. Tan delta $(\tan \delta)$ signals, storage modulus $\left(E^{\prime}\right)$ and loss modulus $\left(E^{\prime \prime}\right)$ of (PAZ-E)s were measured as functions of the sample temperature and $\tan \delta$ signals of (PAZ-E)s, $E^{\prime}$ and $E^{\prime \prime}$ of P-9, $\mathrm{P}-10, \mathrm{P}-11, \mathrm{P}-12, \mathrm{P}-13$ and $\mathrm{P}-14$ are shown in figure 9. 

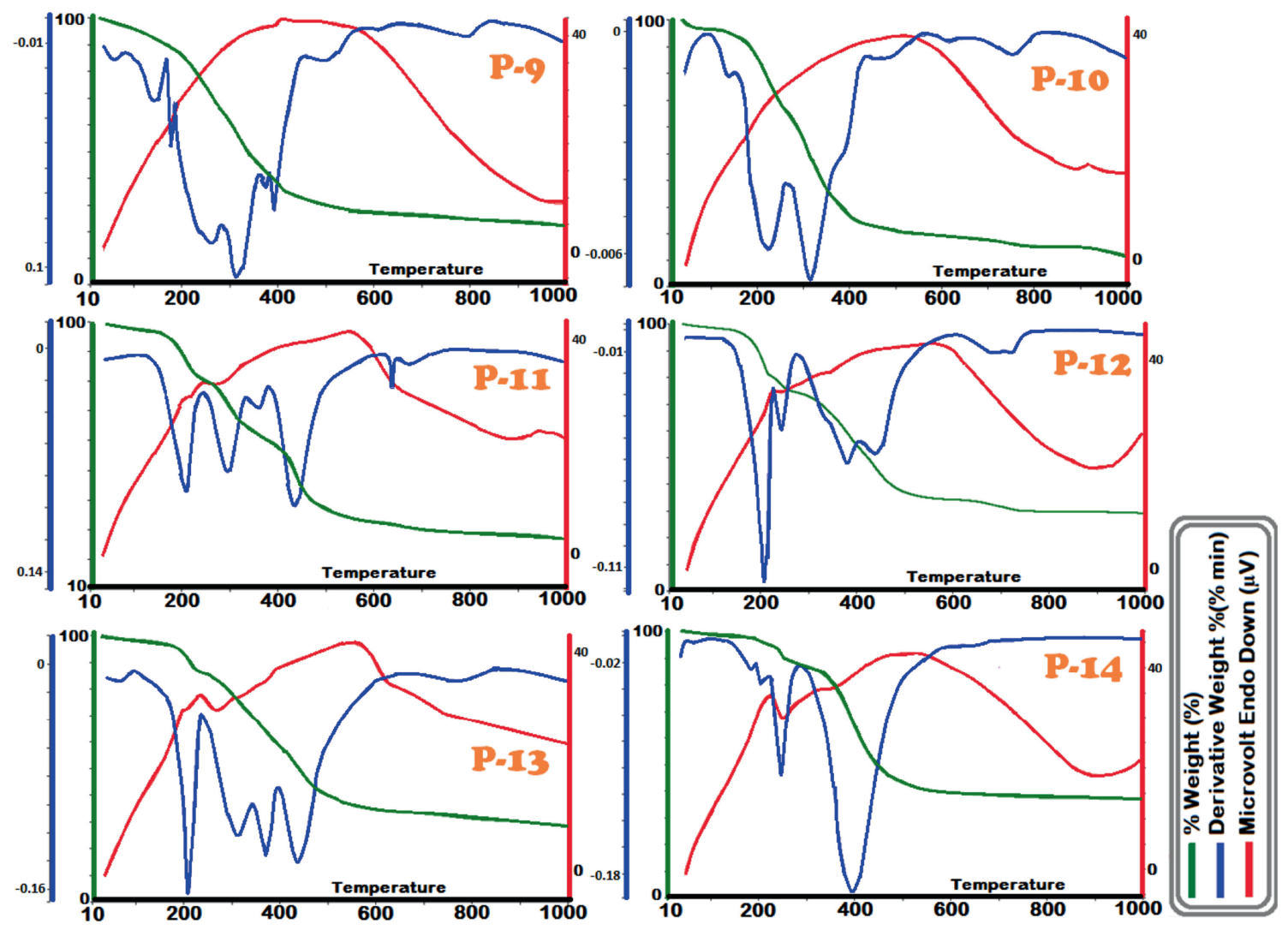

Figure 7. Thermal (TG, DTG and DTA) curves of the obtained (PAZ-E)s.

Table 4. Thermal characteristics data of SBs and (PAZ-E)s.

\begin{tabular}{llrrrrrrrrr}
\hline Compounds & & P-9 & P-10 & P-11 & P-12 & P-13 & P-14 & SB-9 & SB-10 & SB-11 \\
\hline \multirow{2}{*}{ First step } & $T_{\text {on }}^{\mathrm{a}}$ & 200 & 198 & 200 & 200 & 210 & 250 & 274 & 266 & 220 \\
& $T_{\text {max. }}^{\mathrm{b}}$ & 261 & 225 & 208 & 208 & 210 & 255 & 297 & 304 & 296 \\
& $T_{\text {end }}^{\mathrm{c}}$ & 285 & 269 & 249 & 227 & 240 & 290 & 354 & 430 & 382 \\
& \% & 35 & 36 & 20 & 20 & 14 & 13 & 67 & 61 & 48 \\
Second step & $T_{\text {star. }}^{\mathrm{e}}$ & 285 & 269 & 249 & 227 & 240 & 290 & 354 & 430 & 382 \\
& $T_{\text {max. }}$ & 312 & 314 & 295 & 244 & 440 & 396 & 373 & 463 & 448 \\
& $T_{\text {end }}$ & 582 & 441 & 340 & 411 & 1000 & 1000 & 433 & 1000 & 629 \\
& $\%$ & 38 & 41 & 16 & 30 & 58 & 51 & 11 & 30 & 19 \\
Third step & $T_{\text {star. }}$ & 582 & 441 & 340 & 411 & - & - & 433 & - & 629 \\
& $T_{\text {max. }}$ & 789 & 756 & 435 & 440 & - & - & 739 & - & 736 \\
& $T_{\text {end }}$ & 1000 & 1000 & 1000 & 1000 & - & - & 1000 & - & 1000 \\
& $\%$ & 5 & 11 & 38 & 25 & - & - & 18 & - & 21 \\
& $T_{20}^{\mathrm{f}}$ & 247 & 216 & 256 & 222 & 292 & 358 & 267 & 299 & 274 \\
& $T_{50}^{\mathrm{g}}$ & 358 & 312 & 422 & 422 & 437 & 440 & 307 & 440 & 397 \\
& Char & 22 & 22 & 27 & 25 & 28 & 36 & 4 & 6 & 12 \\
\hline
\end{tabular}

${ }^{\mathrm{a}}$ Onset temperature.

${ }^{\mathrm{b}}$ Maximum weight loss temperature.

${ }^{\mathrm{c}}$ Thermal degradation finished temperature.

${ }^{\mathrm{d}}$ Weight loss at the steps.

${ }^{\mathrm{e}}$ Thermal degradation started temperature.

$\mathrm{f}_{20 \%}$ wt loss.

$\mathrm{g} 50 \%$ wt loss.

${ }^{\mathrm{h}} \mathrm{Char}$ at $1000^{\circ} \mathrm{C}$. 

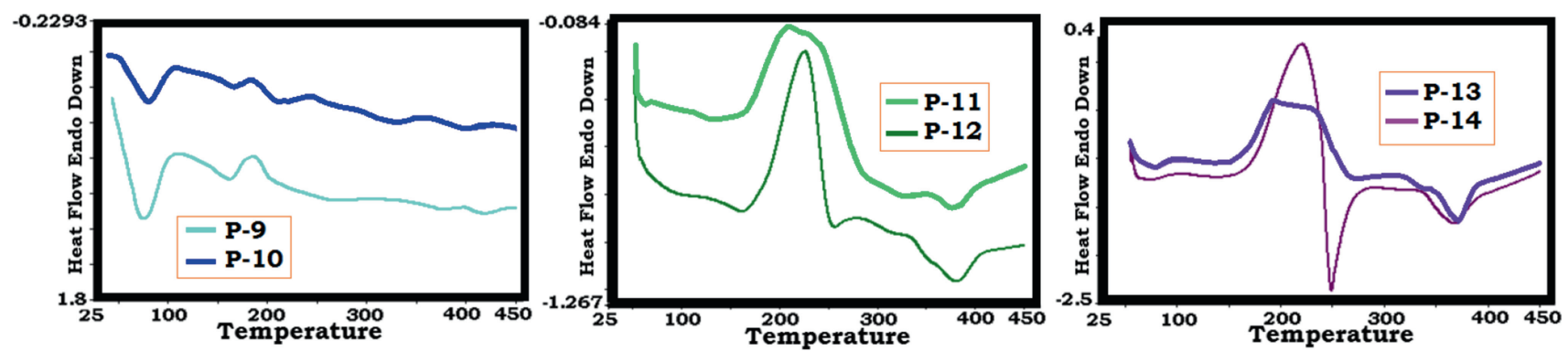

Figure 8. DSC thermograms of the obtained (PAZ-E)s.
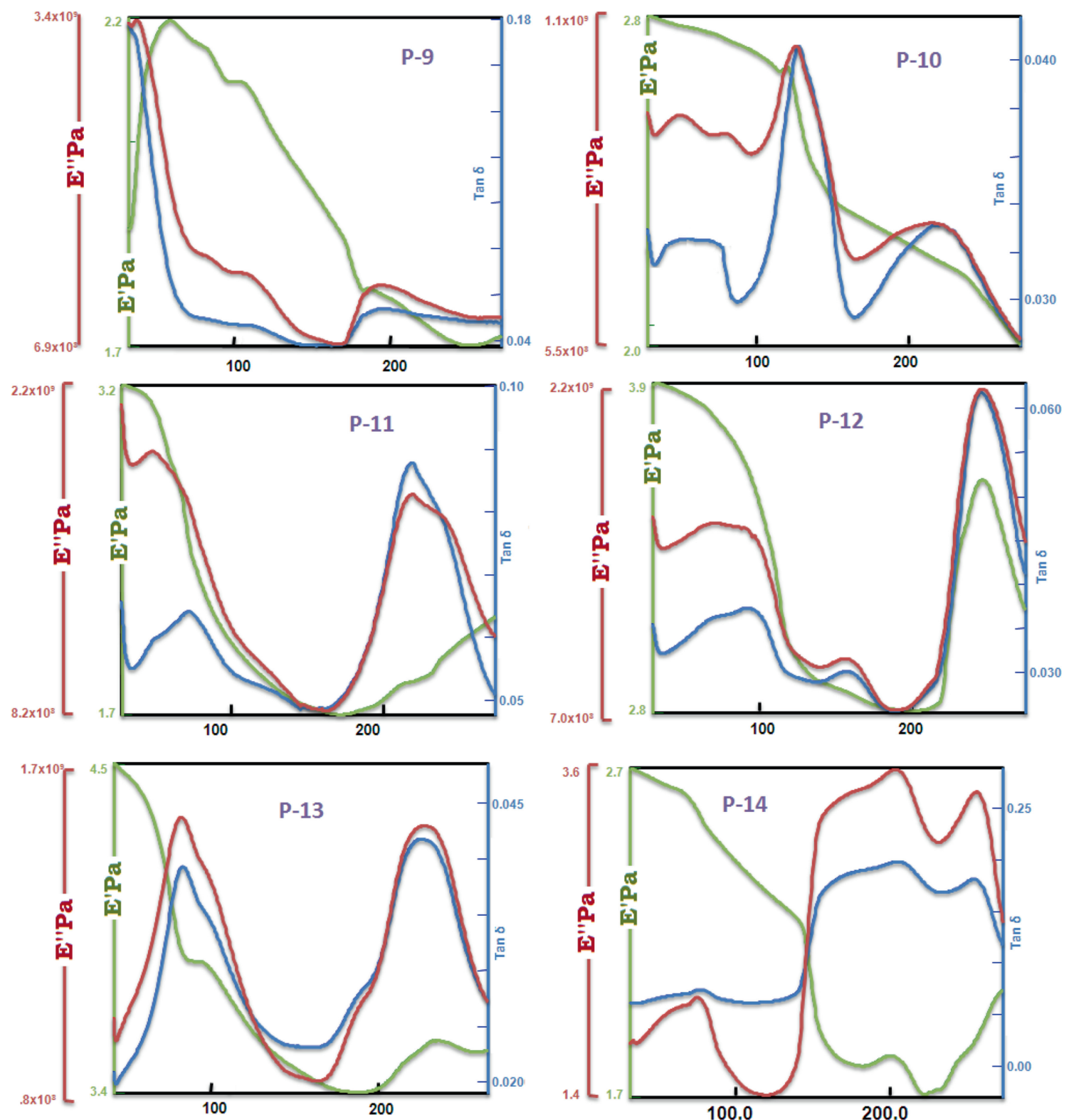

Figure 9. DMA curves and $\tan \delta, E^{\prime}$ and $E^{\prime \prime}$ for (PAZ-E)s. 

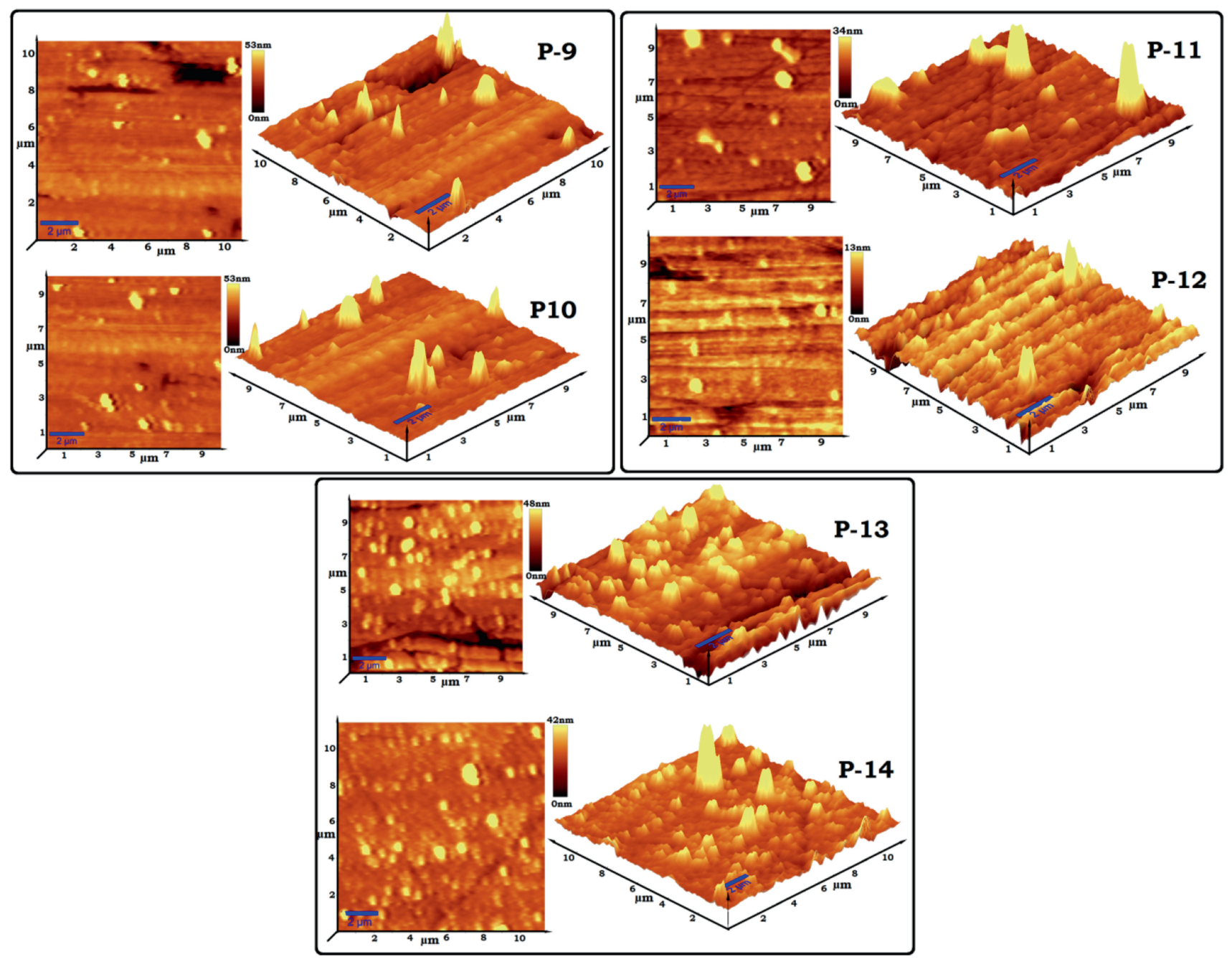

Figure 10. AFM images of (PAZ-E)s.

DMA analysis of the (PAZ-E)s was performed with a single cantilever mode. $E^{\prime \prime}, E^{\prime}$ and $\tan \delta$ were tested as the functions of the sample temperature. DMA analyses of (PAZ-E)s were carried out in the range of $20-350^{\circ} \mathrm{C}$. Tan $\delta$ curves of the (PAZ-E)s are shown in figure 9. The temperature related to first capacious peak of $\tan \delta$ is specified as the $T_{\mathrm{g}}$ and the obtained $T_{\mathrm{g}}$ values of P-9, P-10, P-11, P-12, P-13 and P-14 (PAZ-E)s were calculated as 130, 128, 115, 150, 157 and $150^{\circ} \mathrm{C}$, respectively. With reference to DMA curves and data, para-(PAZ-E)s are more durable than ortho- and meta-(PAZE)s. When analogized to $T_{\mathrm{g}}$ acquired from DMA and DSC, the $T_{\mathrm{g}}$ values of (PAZ-E)s are found to be nearly the same with a small difference in two different techniques.

\subsection{Topographic and morphological properties}

AFM analyses were used to clarify the alteration of morphological and the phase properties of the (PAZ-E)s.
Figure 10 shows 3D images, topographic photographs and phase images of P-9, P-10, P-11, P-12, P-13 and P-14. Root mean square roughness values $\left(S_{\mathrm{q}}\right)$ for the mentioned (PAZ-E)s are 174, 132, 194, 280, 182 and 167 $\mathrm{nm}$. As for the AFM views of the (PAZ-E)s, the surfaces of (PAZ-E)s seem to be scattered and non-homogeneous owing to their relatively aspheric shapes [37]. Ortho-(PAZE)s (P-9 and P-10) had similar surface morphologies like meta (P-11 and $\mathrm{P}-12)$ and para (P-13 and $\mathrm{P}-14)$ (PAZ-E)s.

SEM techniques were used to interpret the surface morphology of the (PAZ-E)s. Figure 11 shows the SEM images of P-10, P-12, P-13 and P-14 polyester. According to SEM photographs of (PAZ-E)s; ortho- PAZ-E (P-10) had rigid, meta- PAZ-E (P-12) had rough and para- PAZ-E (P-14) had porous shapes. It is seen that AFM and SEM images had a similar surface appearance. PAZ-E (P-14) showed a porous structure. 

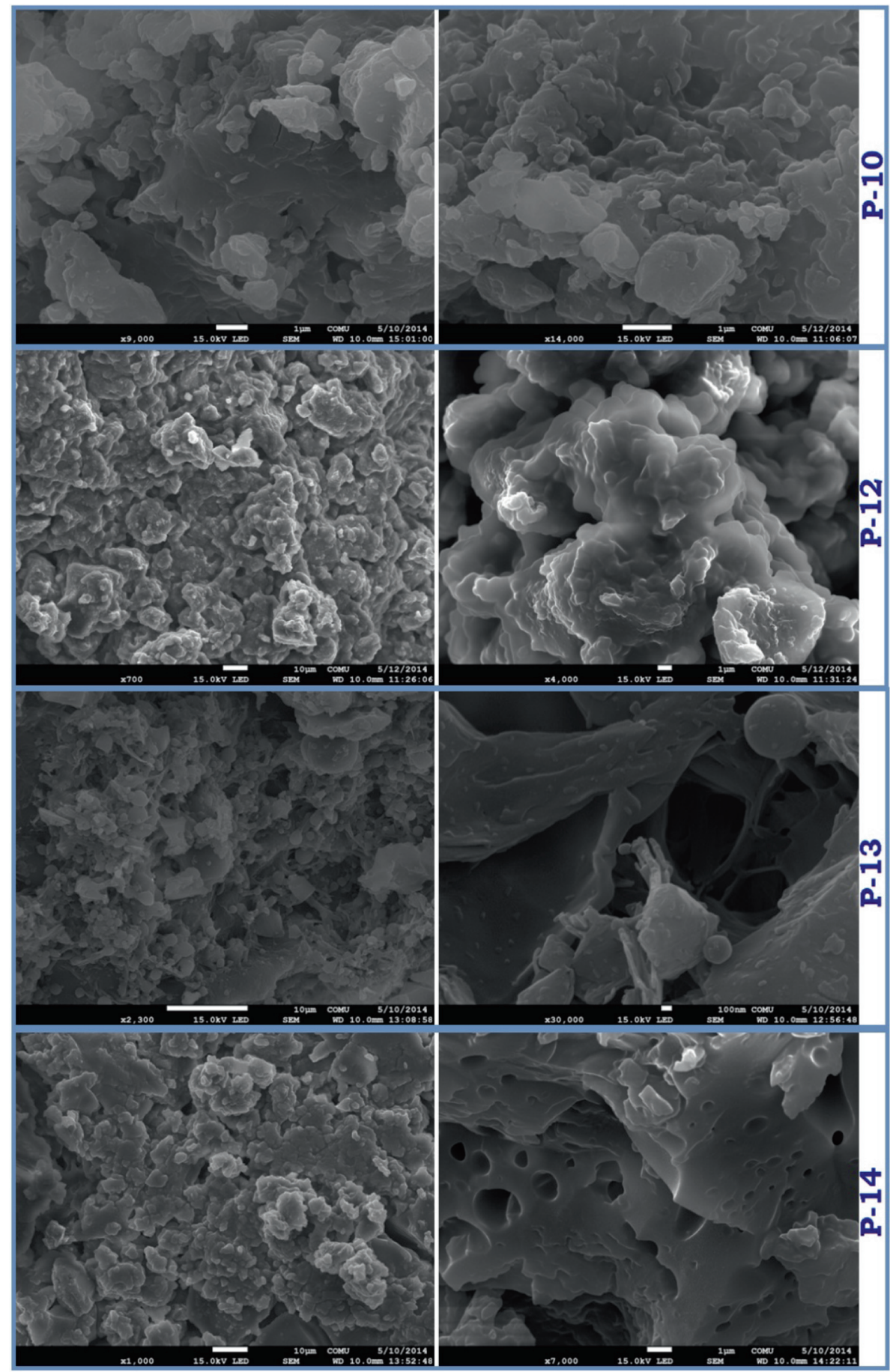

Figure 11. FESEM images of P-10, P-12, P-13 and P-14, respectively.

\section{Conclusions}

A new series of (PAZ-E)s with changing ortho, meta and para positions were cleanly synthesized from diols of SBs. The chemical structures were successfully verified by ${ }^{1} \mathrm{H}-\mathrm{NMR}$, ${ }^{13}$ CNMR and FTIR spectroscopies. Thermal analysis data showed that the obtained (PAZ-E)s had high thermal characteristics with $T_{\mathrm{on}}$ between 198 and $250^{\circ} \mathrm{C}$. According to the TGA results, chars of (PAZ-E)s were also high, especially for P-14. These (PAZ-E)s had high thermal resistance, especially para-positioned (PAZ-E)s. All these (PAZ-E)s emitted different colours (green-blue-pink) in DMF solution, respectively. Also, the fluorescence characteristics of ortho-positioned (PAZ-E)s were high compared to others. All these findings prove that ortho-, meta- and para-(PAZ-E)s are good candidates for commercial strict 
requirements, structural materials and thermally stable lightemitting materials.

\section{References}

[1] Berendjchi A, Khajavi R, Yousefic A A and Yazdanshenas M E 2016 Appl. Surf. Sci. 363264

[2] Harifi T and Montazer M 2014 Ind. Eng. Chem. Res. 531119

[3] Arbab A A, Sun K C, Sahito I A, Qadira M B and Jeong S H 2015 Phys. Chem. Chem. Phys. 1712957

[4] Marin L, Cozan V and Bruma M 2006 Polym. Adv. Technol. 17 664

[5] Marin L, Cozan V, Bruma M and Grigoras V C 2006 Eur. Polym. J. 421173

[6] Zhang S J, Li Y F, Wang X L, Yin D X, Shao Y and Zhao X 2005 Chin. Chem. Lett. 161165

[7] Utkarsh S, Rao K V and Rakshit A K 2003 J. Polym. Sci. Pol. Chem. 88152

[8] Kausar A, Zulfiqar S, Ahmad Z and Sarwar M I 2010 Polym. Degrad. Stabil. 951826

[9] Huo H, Mo S, Sun H, Yang S and Fan L 2012 e-Polymer 12 566

[10] Ghaemy M and Mighani H 2010 J. Appl. Polym. Sci. 1182496

[11] Koole M, Frisenda R, Petrus M L, Perrin M L, Zant H S J and Dingemans T J 2016 Org. Electron. 3438

[12] Farcas A and Grigoras M 2001 High. Perform. Polym. 13201

[13] Doğan F, Kaya İ and Temizkan K 2014 J. Macromol. Sci. Part A: Pure Appl. Chem. 51948

[14] Dineshkumar S, Muthusamy A and Chandrasekaran J 2017 J. Mol. Struct. 1128730

[15] Lv A, Cui Y, Du F S and Li Z C 2016 Macromolecules 498449

[16] Gennes P G, Chung T C and Petchsux A 1975 C R Acad. Sci. Ser. B 281101
[17] Perz V, Bleymaier K, Sinkel C, Kueper U, Bonnekessel M, Ribitsch D et al 2016 New Biotechnol. 33295

[18] Sek D 1984 Eur. Polym. J. 20923

[19] Flory P J 1956 Proc. Roy. Soc. London A 23460

[20] Fabbri M, Soccio M, Gigli M, Guidotti G, Gamberini R, Gazzano M et al 2016 Polymer 83154

[21] Percec V and Yourd R 1989 Macromolecules 22524

[22] Ahner J, Micheel M, Geitner R, Schmitt M, Popp J, Dietzek B et al 2017 Macromolecules $\mathbf{5 0} 3789$

[23] Iwan A and Sek D 2008 Prog. Polym. Sci. 33289

[24] Balagi K and Murugavel S C 2011 J. Polym. Sci., Part A: Polym. Chem. 494809

[25] Osada I, Vries H, Scrosati B and Passerini S 2012 Angew. Chem. Int. Ed. $\mathbf{5 5} 500$

[26] Muraria N M, Hwanga Y J, Kimb F S and Jenekhea S A 2016 Org. Electron. 31104

[27] Shi Y and Yu G 2016 Chem. Mater. 282466

[28] Islam M S, Deng Y, Tong L, Faisal S N, Roy A K, Minett A I et al 2016 Carbon 96701

[29] Lyon S B, Bingham R and Mills D J 2017 J. Inorg. Organomet. Polym. 1022

[30] Avcı A, Kamacı M, Kaya İ and Yıldırım M 2015 Mater. Chem. Phys. 163301

[31] Kaya İ and Culhaoglu S 2009 Polimery 54266

[32] Kaya İ, Aydın A and Temizkan K 2013 Chinese J. Polym. Sci. 311632

[33] Karaer H, Kaya İ and Aydın H 2017 Polimery 62170

[34] Doğan F, Kaya İ and Temizkan K 2016 J. Mol. Catal. B: Enzymatic 133234

[35] Kaya İ, Avcı A and Temizkan K 2017 Macromol. Res. 25 45

[36] Şenol D, Kolcu F and Kaya İ 2016 J. Fluoresc. 26 1579

[37] Temizkan K and Kaya İ 2017 Polym. Bull. 742575 